\title{
Covid-19: Africa Versus the World
}

\author{
Oderinde GP ${ }^{1 *}$, Musa $\mathrm{SA}^{2}$, Ndu $\mathrm{M}^{2}$, Adeyinka $\mathrm{A}^{3}$ and Abdulazeez $\mathrm{MA}^{2}$ \\ ${ }^{1}$ Genetic Anthropology Unit, Department of Anatomy, Ahmadu Bello University, \\ Zaria, Nigeria \\ ${ }^{2}$ Department of Anatomy Ahmadu Bello University, Zaria, Nigeria \\ ${ }^{3}$ Nigeria Institute of Medical Research, Yaba, Lagos, Nigeria \\ *Corresponding Author: Oderinde GP, Genetic Anthropology Unit, Department of \\ Anatomy, Ahmadu Bello University, Zaria, Nigeria.
}

\author{
Received: September 25, 2020 \\ Published: December 14, 2020 \\ (C) All rights are reserved by Oderinde GP., \\ et al.
}

\begin{abstract}
Africa is the largest and most populous continent after Asia but with highest number of countries. Africa represents about $1 / 6$ of the world population but Africa is the least represented in the world Genomic population. During the outbreak of COVID-19 there was much concern about Africa due to numerous inadequate health facilities. Data was gotten from the official World Health Organization (WHO) website and was cleaned and arranged in Microsoft Excel version 2019. The data was then visualized using Tableau Public version 10.4. Africa was compared to other regions in two categories: New cases and Deaths. In the number of new cases and deaths, Africa and Western Pacific regions were lower than other regions with the number in Africa being slightly higher than that of Western Pacific from $23^{\text {rd }}$ May and $30^{\text {th }}$ May respectively. The results showed that Africa performs better when compared with the rest of the world in new cases and deaths rate as a result of COVID-19. There is need for equal representation of Africa populace in the genomic world data.
\end{abstract}

Keywords: COVID-19; Corona-Virus; African; Healthcare

\section{Introduction}

A range of human diseases with little or no known pathology, etiology and treatment still exist and could be pandemic if it is an infectious disease, in cases like the Spanish flu, Middle East Respiratory Syndrome, Chicken pox among others. The spread of the 2019 novel coronavirus diseases (COVID-19) or the severe acute respiratory syndrome originated from Wuhan city of Hubei Province of China before spreading to the rest of the world with the exception of Antarctica [1].

Coronaviruses are seen under electron microscope as enveloped positive sense RNA viruses with sizes ranging from $60 \mathrm{~nm}$ $140 \mathrm{~nm}$ in diameter with spike like projections on its surface giving it the crown like appearance where the name coronavirus was deduced [2]. Four corona viruses have being identified namely HKU1,
NL63, 229E and OC43 which have been in circulation in humans, and generally cause mild respiratory disease.

There are two reported events of crossover of animal beta coronaviruses in the past two decades; wherein crossover of animal beta coronaviruses to humans has resulted in severe disease. In 2002 - 2003 which was the first instance, coronavirus of the beta genera with its origin from bats crossed over to humans via an intermediary host of palm civet in the Guangdong province of China. About 8400 people were affected, mostly in Hong Kong and China and caused about 900 deaths (mortality 11\%) before being contained [3].

About ten (10) years later in 2012, the Middle East Respiratory syndrome coronavirus (MERS-CoV), which also originated from bat, started in Saudi Arabia through dromedary camel as the in- 
termediate host and affected about 2500 people and caused about 900 deaths (fatality rate $34 \%$ ) [4].

The spread of the novel coronavirus disease (COVID-19) to Africa was officially said to have been on 14 February 2020 with the first reported confirmed case being in Egypt (WHO, 2020) and the first confirmed case in sub-Saharan Africa in Nigeria (WHO, 2020). Most of the known imported cases to Africa arrived from the United States and Europe instead from China where the virus was first confirmed [5]. It is believed to be widespread of under-reporting especially in African countries with less developed healthcare systems [6].

There were worries about the spread of COVID-19 in Africa because of the numerous inadequate healthcare systems in Africa, problems related to lack of equipment and funding, insufficiently trained healthcare workers and inefficient data transmission. Uncontrollable widespread of the pandemic in Africa and the huge economic problems arising from it were cause for fear [5].

Two (2) months after the index case of COVID-19 in Africa, there were insufficient supply of ventilators: 41 countries had only 2,000 ventilators among them, and ten countries had no ventilators at all. Basic materials like sanitizer and water were subject to shortage supply in some parts of the continent [7]. The Regional Director of WHO Africa stated that physical distancing and hand washing might be a challenge in some places in Africa due to cultural and religious practice. Also lockdown maybe difficult to achieve, and challenges might be exacerbated due to the incidence of diseases such as AIDS, malaria, cholera, and tuberculosis [7].

Speculation like Testing Based Strategy was proposed by expert to allow African countries reduce lockdowns that might impose huge hardship on those who are day to day income earners to be able to feed themselves and their families. There is increased threat of food crisis in several African countries. The United Nations proposed that about 74 million test kits and 30,000 ventilators will be considered necessary by the continent's 1.3 billion people in 2020 in the best circumstances [8] and WHO have helped many countries in Africa to set up COVID-19 testing centers.

Coronavirus has spread to all the African countries with Lesotho being the last African nation to report a case of COVID-19 (WHO, 2020), there were no reported cases in French Southern Territories, Saint Helena and British Indian Ocean Territory as of May 13, 2020. Regardless of a steady climb in the number of confirmed cases, Africa continues to lag behind the global curve for infections and deaths rate. The continent witnessed a grave economic impact as a result of the pandemic, which damaged the continent's growing middle class and threatened to add to the rates of deficiency and extreme poverty [9].

\section{Materials and Methods}

Data was gotten from the official World Health Organization (WHO) website. The period in view in this work is from February 2020 to July 2020. From the period being studied, Saturdays were picked and the statistics for every Saturday of every month in this period was collected. The data was cleaned and arranged in Microsoft Excel version 2019. The data was then visualized using Tableau Public version 10.4.

\section{Results}

The data was obtained from the WHO website and was analyzed using Excel and visualized using Tableau Public. The values show new cases and deaths for every Saturday in the period between March and July.

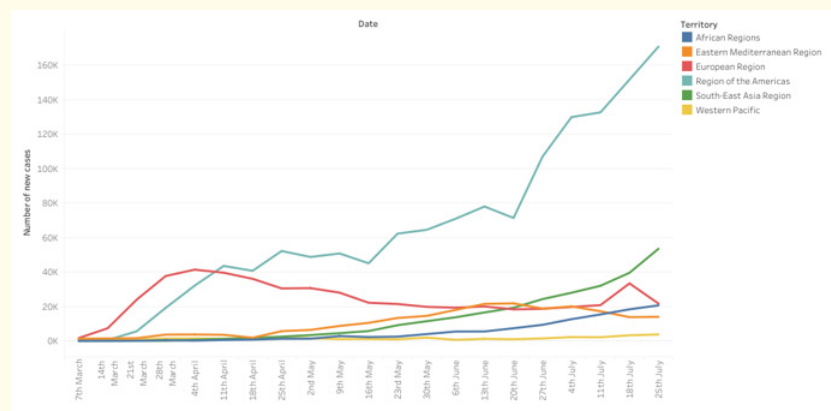

Figure 1: Line charts showing new cases of Corona virus from March and July across the territories.

From the line chart, the European region is showed an increase in the new cases of Corona virus from $14^{\text {th }}$ March and gradually reduced from $25^{\text {th }}$ April till the spike in $18^{\text {th }}$ July. The American region kept increasing from $21^{\text {st }}$ March till the $25^{\text {th }}$ July. The Eastern Mediterranean, South-East Asia, African and Western Pacific regions were relatively low when compared to the European and American regions, the Eastern Mediterranean region increased gradually $25^{\text {th }}$ April and kept increasing till $27^{\text {th }}$ June from which there was a gradual decrease while South- East Asian region started to increase from $2^{\text {nd }}$ May and has kept increasing. African regions show a spike in $9^{\text {th }}$ May after which it gradually increases from $30^{\text {th }}$ May while the Western Pacific have the lowest new cases in this period with periodic spikes. 


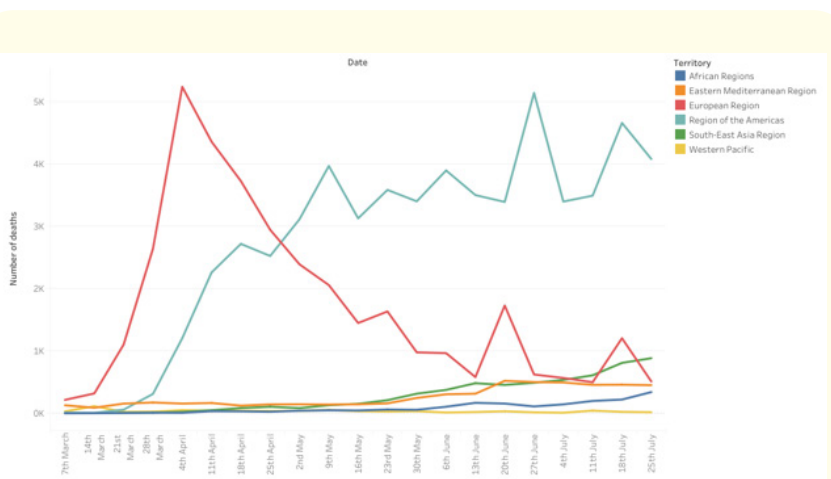

Figure 2: Line charts showing deaths from Corona virus from March and July across the territories.

From the chart above, the number of deaths from Corona virus in the European region showed spikes throughout the period being researched which the highest and longest spike being the one that began on $21^{\text {st }}$ March and ended on $16^{\text {th }}$ May while in the American region there was a gradual increase in the number with spikes from 28 ${ }^{\text {th }}$ March. The Eastern Mediterranean region experienced a plateau up till $30^{\text {th }}$ May where it increased gradually till the end of the period in view which is the same for South-East Asia and African regions which experienced increase from $18^{\text {th }}$ April and $6^{\text {th }}$ June respectively. The Western Pacific region experienced a plateau with negligible spikes.

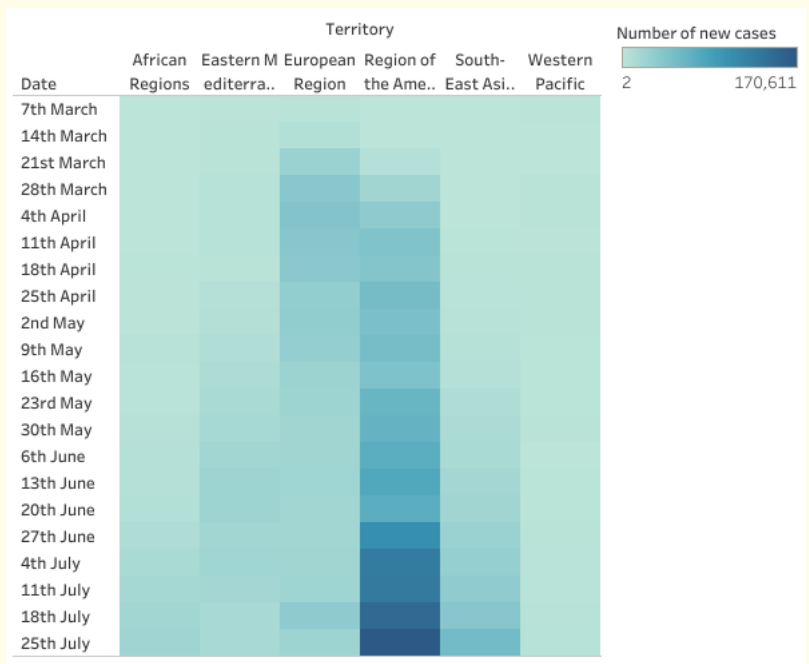

Figure 3: Heat map showing new cases of Corona virus from March and July across the territories.
The heat map shows intensity of new cases of Corona virus and its distribution across the date and territories. The dark colors show the areas with the high range of new cases while the light colors show the areas with the low range of new cases.

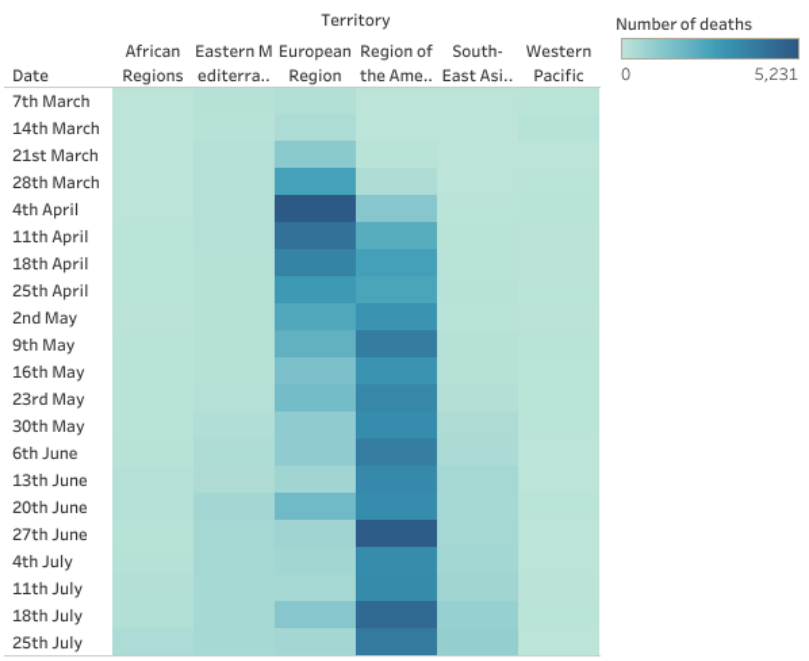

Figure 4: Heat map showing deaths from Corona virus from March and July across the territories.

The heat map shows intensity of deaths from Corona virus and its distribution across the date and territories. The dark colors show the areas with the high range of deaths while the light colors show the areas with the low range of deaths.

\section{Discussion and Conclusion}

Even with cases of under-reporting and un-reporting case of COVID-19 in some African countries, the impact of COVID-19 on the African continent do not seems to have occurred as predicted by health experts with no news on over-burden morgue or health facilities. Some of the theories that has postulated to explain this phenomenon include the continent climatic condition, Africa youthful population with a median age of 19.4 years and that $60 \%$ of the population is under 25 , indirect protection from other treatments that were intended to treat other infectious diseases like malaria or tuberculosis and also Africans are exposed to a lot of diseases, so it's possible that there is natural genetic immunity [10].

Research has shown that people from different parts of the world differ in their susceptibility to developing infectious diseases 
[11]. The burden of infectious diseases is probably the most important factor shaping immune responses throughout human history, given that natural selection driven by pathogens is crucial for influencing the patterns of variability of genes involved in host defense [12]. Interspecies and intraspecies studies have shown that both purifying and positive selection are crucial processes that influence and modulate the functionality of genes related to immunity and host defense [13].

Effective host defense against pathogenic microorganisms is a crucial condition for the survival of any multicellular organism, and a complex immune system has evolved to fulfill this task. During the evolutionary history of our species, infections shaped the genetics and function of the immune system, leading to variation of host defense responses in human populations as a result of local infectious pressures and migration events [14].

Natural selection contributed to the differences in immune responses observed between populations by providing genome-wide support that regulatory variants associated with different responsiveness to immune challenges have been targeted by positive selection. Selection appears to have increased the frequency of the African -specific reQTL (mapped expression quantitative trait loci) leading to stronger CCR1 downregulation following TLR1/2 (Tolllike Receptor) activation, which suggest that CCR1 downregulation conferred a selective advantage in Africans, likely to favour diminished inflammation [15].

A study observed stronger reaction to infection induced in macrophages from those of African descent, mainly among inflammatory response genes [16]. Other studies have shown that European-Americans have lower frequencies of alleles associated with pro-inflammatory response, levels of circulating C-reactive protein and a much lower rate of inflammatory diseases than AfricanAmerican individuals [17-19].

Evolutionary pressure could explain these differences, after out of Africa human migration they were exposed to lower pathogen levels [27], which reduced the want for strong, costly pro-inflammatory signals. Change in this way may have been privileged due to the disadvantageous consequences of acute or chronic inflammation, which are major contributors to the development of autoinflammatory and autoimmune diseases [20].

Evidence shows that older populations are hardest hit by the coronavirus. There are many younger population in Sub-Saharan
Africa when compared with the population of the United States, China, the European Union, and other areas experiencing widespread infection. The median age of China and the United States is 38 while it is 43 in the European Union, but it is 19 in sub-Saharan Africa [21]. In Italy, which has had one of the highest COVID-19 mortality rates in the world, $23 \%$ of the population is over age 65 , while only $3 \%$ of Africa population is over 65. Nigeria, which is Africa's most populous country, about half of the population is under age 15 [22].

Advance in age causes the immune system to undergo intense remodeling and decline, with main impact on wellbeing and survival $[23,24]$. Immune senescence predisposes older adults to a higher risk of acute viral and bacterial infections. Infectious diseases are one of the most common causes of death among the aged in the developed countries. The ageing immune system fails to maintain full tolerance to self-antigens, with an increased incidence of autoimmune disease [25]. This is probably due to lymphopaenia occurring with age, leading to excess homeostatic lymphocyte proliferation [26] as well as a decrease in regulatory T-cell function and decreased clearance of apoptotic cells by macrophages [23].

\section{Bibliography}

1. Wang C., et al. "A novel coronavirus outbreak of global health concern". Lancet 398.10223 (2020): 470-473.

2. Richman DD., et al. "Clinical Virology". $4^{\text {th }}$ edition. Washington: American Society of Microbiology Press (2016).

3. Chan-Yeung M and Xu RH. "SARS: epidemiology". Respiration 8 (2003): S9-S14.

4. Tanu S. "A Review of Coronavirus Disease-2019 (COVID-19)". Indian Journal of Pediatrics 87.4 (2020): 281-286.

5. Maclean R. "Africa Braces for Coronavirus but Slowly". The New York Times (2020).

6. Jason B and Abdalle AM. "Somali medics report rapid rise in death as Covid-19 fears grow". The Guardian (2020).

7. Maclean R and Marks S. "10 African Countries have no Ventilators. That's only part of the Problem". The New York Times (2020).

8. Burke J. "It's just beginning here: Africa turns to testing as pandemic grips the continent" (2020).

9. Dahir AL. "Coronavirus is Battering Africa's Growing Middle Class” (2020). 
10. Olivier M. "Coronavirus: Unpacking the theories behind Africa's low infection rate". The Africa Report (2020).

11. Cell Press. Europeans, Africans have different immune systems, and Neanderthals are partly to thank". Science Daily (2020).

12. Fumagalli M and Sironi M. "Human genome variability, natural selection and infectious diseases". Current Opinion in Immunology 30 (2014): 9-16.

13. Grossman SR., et al. "Identifying recent adaptations in largescale genomic data”. Cell 152.4 (2013): 703-713.

14. Dannemann M., et al. "Introgression of Neandertal- and Denisovan-like Haplotypes Contributes to Adaptive Variation in Human Toll-like Receptors". American Journal of Human Genetics 98.1 (2016): 22-33.

15. Quach H., et al. "Genetic Adaptation and Neandertal Admixture Shaped the Immune System of Human Populations". Cell 167.3 (2016): 643-656.

16. Nédélec Y., et al. "Genetic Ancestry and Natural Selection Drive Population Differences in Immune Responses to Pathogens". Cell 167.3 (2016): 657-669.

17. Ness RB., et al. "Differential distribution of allelic variants in cytokine genes among African Americans and White Americans". American Journal of Epidemiology 160 (2004): 10331038.

18. Kelley-Hedgepeth A., et al. "Ethnic differences in C-reactive protein concentrations". Clinical Chemistry 54 (2008): 10271037.

19. Pennington R., et al. "Group differences in proneness to inflammation. Infection, genetics and evolution". Journal of Molecular Epidemiology and Evolutionary Genetics of Infectious Diseases 9 (2009): 1371-1380.

20. Okin D and Medzhitov R. "Evolution of inflammatory diseases". CB 22.17 (2012): R733-R740.

21. Kaseje N. "Why Sub-Saharan Africa Needs a Unique Response to COVID-19". World Economic Forum (2020).

22. Kaned T and Ashford LS. "Sub-Saharan Africa's Demographic and Health Characteristics Will Influence the Course of the COVID-19 Pandemic". PRB (2020).

23. Weiskopf D., et al. "The aging of the immune system". Trans Inter 22.11 (2009): 1041-1050.
24. Jiang N., et al. "Lineage structure of the human antibody repertoire in response to influenza vaccination". Science Translational Medicine 5.171 (2013): 171ra19.

25. Goronzy JJ and Weyand CM. "Aging, autoimmunity and arthritis: T-cell senescence and contraction of T-cell repertoire diversity - catalysts of autoimmunity and chronic inflammation". Arthritis Research and Therapy 5.5 (2003): 225-234.

26. Sheu TT., et al. "Premature CD4+ T cell aging and its contribution to lymphopenia-induced proliferation of memory cells in autoimmune-prone non-obese diabetic mice". PloS one 9.2 (2014): e89379.

27. Guernier V., et al. "Ecology drives the worldwide distribution of human diseases". PLoS Biology 2 (2004): e141.

\section{Assets from publication with us}

- Prompt Acknowledgement after receiving the article

- Thorough Double blinded peer review

- Rapid Publication

- Issue of Publication Certificate

- High visibility of your Published work

Website: $\underline{w w w}$.actascientific.com/

Submit Article: www.actascientific.com/submission.php

Email us: editor@actascientific.com

Contact uS: +919182824667 